\title{
Prey switching of cod and whiting in the North Sea
}

\author{
Anna Rindorf*, Henrik Gislason, Peter Lewy \\ Danish Institute for Fisheries Research, Charlottenlund Castle, 2920 Charlottenlund, Denmark
}

\begin{abstract}
Predator-prey switching may stabilise predator-prey interactions, promote co-existence of prey that share a common predator, and increase the overall stability of homogeneous systems of interacting species. This study presents an investigation of prey switching of 2 major North Sea fish predators, cod Gadus morhua and whiting Merlangius merlangus. Relative food composition derived from analysis of more than 36000 stomachs is compared to the relative density of fish prey reflected by trawl survey catches, and generalised linear models are used to examine how prey switching is affected by predator length and prey species and length. Possible effects of stomach sample size and predator density are also investigated. Prey preference is a decreasing function of the relative density of the prey (negative prey switching), in particular for large cod (40 to $100 \mathrm{~cm}$ ). This was neither the result of variations in stomach sample size, nor of changes in local predator abundance. If not counteracted by compensatory changes in spatial overlap or total food intake, negative switching is likely to destabilise the interactions between cod and whiting and their fish prey.
\end{abstract}

KEY WORDS: Prey switching $\cdot$ Piscivorous fishes $\cdot$ North Sea $\cdot$ Ecosystem stability

\section{INTRODUCTION}

Understanding how the diet of predators depends on the abundance of their prey is a topic of crucial importance in ecology. The food intake of predators determines energy flow through the ecosystem and may have profound effects on the stability of interacting populations. Predators whose preference for a particular prey increases as a function of the abundance of the prey (positive switching or simply switching; Murdoch 1969) stabilise predator-prey equilibria, permit co-existence of competing prey species, and increase overall stability of spatially homogenous ecosystem models (Murdoch \& Oaten 1975, Pelletier 2000). In contrast, a predator whose preference for a prey decreases as a function of the abundance of this prey will maintain its diet composition virtually constant irrespective of changes in prey density, and may destabilise trophic interactions by increasing the predation mortality of a prey species whose abundance declines. Decreasing preference at increasing relative prey abundance has been referred to as anti switching or counter switching
(Chesson 1978, Visser 1981), but in this paper will be called negative switching, as suggested by Chesson (1984).

Several authors have examined prey switching in the laboratory (Manly et al. 1972, Murdoch et al. 1975, Murdoch \& Oaten 1975, Visser 1981, J. Chesson 1984, Kean-Howie et al. 1988, P. L. Chesson 1989). Positive switching has been found when the pursuit of different prey requires different feeding modes or areas (Murdoch et al. 1975, Chesson 1989), possibly due to the desire of the predator to maximise energy intake per unit time (Murdoch \& Oaten 1975). Positive switching has also, however, been found in situations where no apparent energy gain occurs (Manly et al. 1972), and a number of switching models have actually been shown to lead to non-optimal foraging (Holt 1983). Negative switching by aquatic predators has been less frequently reported, but reports of such behaviour do exist (Reed 1969, cited in Murdoch \& Oaten 1975, Visser 1982, Kean-Howie et al. 1988). The explanation for negative switching is largely unknown, but suggestions include the effect of prey actively attempting to avoid the predator when the risk of predation is high 
(Abrams \& Matsuda 1993), the estimation of mean preference from samples consisting of several individuals with different preferences (Chesson 1984), the confusion of the search image of the predator by the more abundant prey (Kean-Howie et al. 1988), and the desire of the predator to maintain a balanced supply of nutrients (Visser 1982).

The results from laboratory studies of prey switching are often difficult to generalise to natural environments where the density of prey is only one of several factors affecting food intake. The heterogeneity of the environment affects the vulnerability of the prey as do external factors affecting the perceptive abilities of the predator (Townsend \& Risebrow 1982, Lipcius \& Hines 1986, Buckel \& Stoner 2000, Essington et al. 2000). Furthermore, the physiological state of the predator and the density of other profitable prey may influence predation on the individual prey types (Werner \& Hall 1974, Bence \& Murdoch 1986, Stephens \& Krebs 1986, Hart \& Ison 1991, van Baalen et al. 2001). All these factors will interact to produce the response of the predator to changes in prey density. With the possible exception of predator condition, these factors do not, however, depend directly on prey density, and although they may render the relationship between predator diet and prey density more difficult to detect, they should not introduce a bias. The underlying relationship between the predator's diet and prey density should be discernable, albeit with substantial variation surrounding it.

The objective of this paper was to examine whether cod Gadus morhua and whiting Merlangius merlangus in the North Sea exhibit prey switching at the population level through a comparison of their relative food composition in the North Sea and the relative local abundance of their fish prey as observed during bottom trawl surveys. If no switching takes place, the relative contribution of 2 different prey items to the diet should be directly proportional to their relative density in the environment. Generalised linear models were used to examine the effect of predator length, prey length, prey species and relative prey density on the relative diet composition of the predators. The effects of stomach sample size, predator density and different assumptions regarding the relative variance of the diet composition and prey abundance data were also investigated.

\section{MODEL, MATERIALS AND METHODS}

Prey switching model. Prey switching is defined by Murdoch (1969) as a change in preference for Prey $i$ relative to Prey $j$ with the relative density of the 2 in the predator's surroundings,

$$
\frac{P_{i}}{P_{j}}=C_{i j} \frac{N_{i}}{N_{j}}
$$

where $P_{i}$ is the number of Prey $i$ eaten, $N_{i}$ is the density of Prey $i$ and $C_{i j}$ is an increasing function of $N_{i} N_{j}^{-1}$. Elton \& Greenwood (1970) generalised this function to

$$
c_{i j}=c_{0, i j}\left(\frac{N_{i}}{N_{j}}\right)^{b-1}
$$

where $c_{0, i j}$ is the ratio between the 2 prey ( $i$ and $j$ ) in the diet when $N_{i}=N_{j}$, and $b$ is a constant describing the degree of switching. Although this model was originally designed to describe positive switching $(b>1)$, it is equally suited for describing negative switching, and the model has previously been used to describe both types (Elton \& Greenwood 1970, Kean-Howie et al. 1988). If $b$ is $>1$, the preference for a prey increases with its relative density and the predator exhibits positive switching (Murdoch \& Oaten 1975); $b<1$ generates negative switching (Chesson 1984, Kean-Howie et al. 1988), and at $b=1$, preference is independent of prey density and no switching takes place. A theoretical example of how the prey ratio in the stomach content changes as a function of the ratio in the predator's surroundings is shown in Fig. 1A for different values of $b$. The resulting relation-
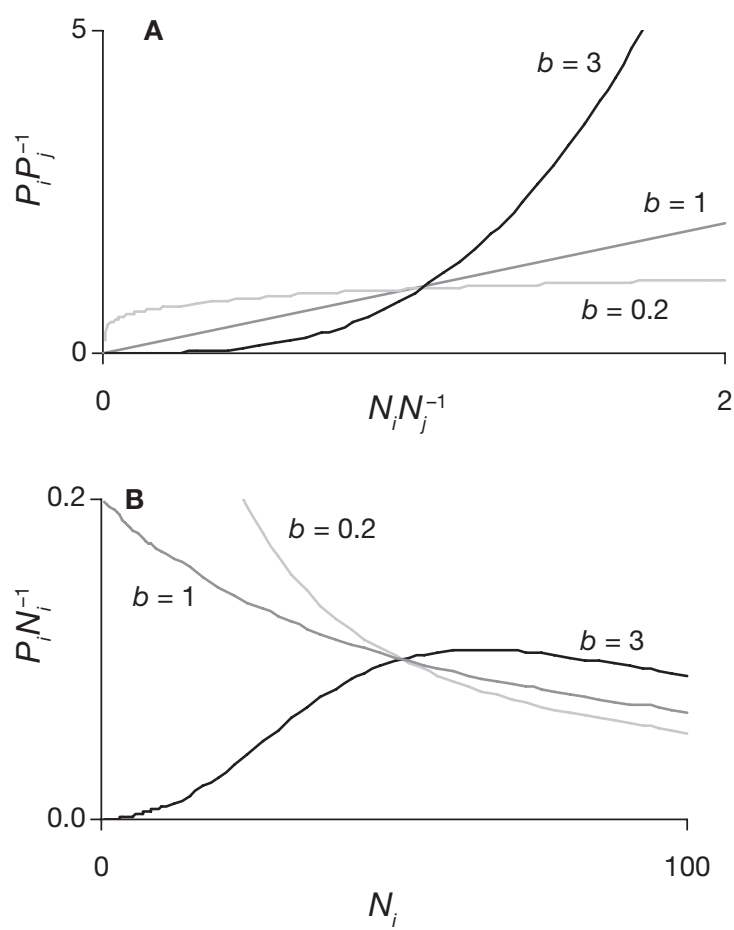

Fig. 1. Effect of prey switching on relative food composition and prey mortality; theoretical examples, (A) relationship between number of Prey $i$ eaten relative to Prey $j\left(P_{i} P_{j}^{-1}\right)$ and abundance of Prey $i$ relative to Prey $j\left(N_{i} N_{j}^{-1}\right)$ (see Eq. 1); (B) mortality (fraction of prey present eaten by predator) of Prey $i$, assuming total consumption and abundance of Prey $j$ to be constant as a function of abundance of Prey $i$ 
ship between prey density and prey mortality is readily derived in the case where density of alternative prey, $N_{j}$, and total food intake of the predator, $P_{\Sigma}$, remain constant. Rearranging Eq. (1), the relationship between density and mortality rate of Prey $i$ becomes

$$
\frac{P_{i}}{N_{i}}=\frac{P_{\Sigma} C_{0, i j} N_{i}^{b-1} N_{j}^{-b}}{1+C_{0, i j} N_{i}^{b} N_{j}^{-b}}
$$

This relationship is shown in Fig. 1B for different values of $b$.

The estimation of $c_{0, i j}$ and $b$ in Eq. (2) is straightforward if food intake can be determined for 2 or several prey types at a number of known density combinations. Information about fish density is often collected by bottom trawling, even though the efficiency of this sampling gear is unknown. It is therefore generally assumed that the catch per time unit of a given species and length group taken by the trawl, $T_{i}$, is directly proportional to its density in the area, $N_{i}$ :

$$
T_{i}=q_{i} N_{i}
$$

where the catchability, $q_{i}$ of the given fish species and length group is generally assumed to be constant for a given vessel, trawl and hauling time (Quinn \& Deriso 1999). Food intake of fishes in the field is often estimated as the product of the total consumption and the weight percentage of each prey in the stomach contents (Armstrong 1982, Hawkins et al. 1985, Seyhan \& Grove 1998):

$$
P_{i}=\frac{n_{i} \bar{w}_{i}}{\sum_{h=1}^{H} n_{h} \bar{w}_{h}} C
$$

where $n_{i}$ is the number of Prey $i$ found in the stomach sample, $\bar{w}_{i}$ is the mean weight of the individual prey in the sample, $C$ is total consumption, $h$ denotes prey type and $H$ is the number of prey types in the diet.

Inserting Eqs. (4) and (5) into Eq. (2) and inserting this into Eq. (1), we get

$$
\frac{n_{i}}{n_{j}}=c_{0, i j}\left(\frac{\bar{w}_{j}}{\bar{w}_{i}}\right)\left(\frac{q_{j}}{q_{i}}\right)^{b}\left(\frac{T_{i}}{T_{j}}\right)^{b}
$$

Assuming that catchability and mean weight of prey, which can be assigned to species and length group in the stomachs, are constant within each species and length group, the term

$$
c_{0, i j}\left(\frac{\bar{w}_{j}}{\bar{w}_{i}}\right)\left(\frac{q_{j}}{q_{i}}\right)^{b}
$$

can be replaced with the constant $d_{i j}$, and the relationship between the number of 2 prey items found in the stomach sample and the number caught by the trawl becomes

$$
\frac{n_{i}}{n_{j}}=d_{i j}\left(\frac{T_{i}}{T_{j}}\right)^{b}
$$

Taking the natural logarithm on both sides, it is evident that $b$ is identifiable as the slope of the (linear) relationship between $\ln \left(n_{i} n_{j}^{-1}\right)$ and $\ln \left(T_{i} T_{j}^{-1}\right)$ :

$$
\ln \left(\frac{n_{i}}{n_{j}}\right)=\ln \left(d_{i j}\right)+b \ln \left(\frac{T_{i}}{T_{j}}\right)
$$

In contrast to $b$, the relative preference for a prey, $c_{0, i j}$, cannot be determined without knowing the relative catchability of the 2 prey types.

Food composition. Cod and whiting were collected from bottom trawl catches obtained in the first quarter of the years 1981, 1985, 1986 and 1987 and in all quarters of 1991 during the stomach sampling projects coordinated by the International Council for Exploration of the Sea (ICES 1988, 1989, 1997, Hislop et al. 1991, Kikkert 1993). On board the vessels, the fishes were sorted into length groups and their stomachs removed. Stomachs from fishes showing signs of regurgitation (Robb 1992) were discarded, and as far as possible replaced by full stomachs in order not to bias the proportion of feeding fish in the samples. To minimise a potential bias introduced by predators feeding in the trawl, prey found in the mouth or pharynx of the predator and very fresh prey found in the stomachs were discarded (ICES 1992). The stomachs which contained food were pooled into a single sample from each predator species, length group and haul, and preserved in $3 \%$ buffered formaldehyde or frozen. In the laboratory, the stomachs were opened and the fish prey identified to species level, counted, measured and weighed. Only information from 4 length groups of cod (30-39.9, 40-49.9, 50-69.9 and 70-99.9 cm) and 2 length groups of whiting $(20-29.9,30-39.9 \mathrm{~cm})$ was used in the present analyses. Other length groups of cod and whiting contained either too few stomach samples or too few fish prey to be included. The resulting food compositions were based on a total of 11899 cod stomachs and 24660 whiting stomachs. Further details about the sampling and analysis of the stomach contents are given in ICES (1989, 1991, 1992, 1997).

We selected 5 frequently encountered fish prey species for analyses of preference: haddock Melanogrammus aeglefinus, herring Clupea harengus, Norway pout Trisopterus esmarkii, sprat Sprattus sprattus and whiting. Prey items $<30 \mathrm{~cm}$ were grouped into $5 \mathrm{~cm}$ length intervals. Prey items $>30 \mathrm{~cm}$ were relatively rare and were not included in the analyses. The length interval used differed between prey species and was 5-25, 10-30, 5-20, 5-15 and 5-30 cm for haddock, herring, Norway pout, sprat and whiting, respectively.

Prey density. The catch per standard trawl haul of the different species and length groups of fish prey obtained during the 'International Bottom Trawl Survey' in the North Sea (ICES 1996a,b) was used to estimate the relative density of prey in each area, year and quarter. An 
average of 2 trawl hauls of 30 min duration were taken in each ICES statistical rectangle $(30 \times 30$ nautical miles $)$. The average number of fishes caught per time unit within each area, $\hat{T}$, was estimated by the $\Delta$-estimator, as suggested by Pennington $(1983,1986)$ by

$$
\hat{T}=\hat{p} \times \hat{C}
$$

where $\hat{p}$ is the estimated proportion of the hauls taken in an area at a given time which contained fish of this particular species and size and $\hat{C}$ is the geometric average number of fish caught in the hauls where the species and size group was caught in the given area and time. The variance of $\ln (\hat{T})$ was estimated as

$$
V[\ln (\hat{T})]=V[\ln (\hat{p})]+V[\ln (\hat{C})]
$$

As only the variance of $\ln (\hat{T})$ is required in the following, variance of $\hat{T}$ was not estimated.

Comparison of prey composition and prey density. Comparison between diet composition and prey density requires information on both stomach contents and trawl catches to be contemporary in time and space. However, as both stomach contents and trawl catches vary considerably between trawl hauls (Pennington et al. 1980, Pennington 1986, Stefánsson 1996, Stefánsson \& Pálsson 1997), comparing the trawl catches of prey with the stomach contents of predators caught in the same haul is likely to produce a relationship which is greatly affected by random noise. Furthermore, the stomachs reflect the food consumption of the predator over a larger temporal scale than the prey abundance estimates derived from short trawl hauls. On the other hand, comparing the two on very large spatial and temporal scales is likely to obscure the relationship, as the predators and prey may not have occurred in the same local areas. As a compromise, it was decided to compare the average trawl catch and stomach contents in each quarter in rectangular areas of $60 \times 60$ nautical miles (Fig. 2).

The majority of the stomachs were sampled from the same hauls used to estimate prey density, but some stomachs were obtained from commercial trawlers, and these were not always collected in the same weeks in which the trawl survey took place. We therefore consider the comparison between diet and prey density as one between the average population of prey and predators on a time scale of a few months in an area of $60 \times 60$ nautical miles, rather than an instant picture of the response of the predator to changes in prey density. Hence, the results will be relevant for characterizing population interactions, but cannot be used to determine the underlying biological mechanisms acting at the local scale.

The ratios between the various prey species length groups in the diet were calculated from the total number of prey items encountered in stomachs sampled in

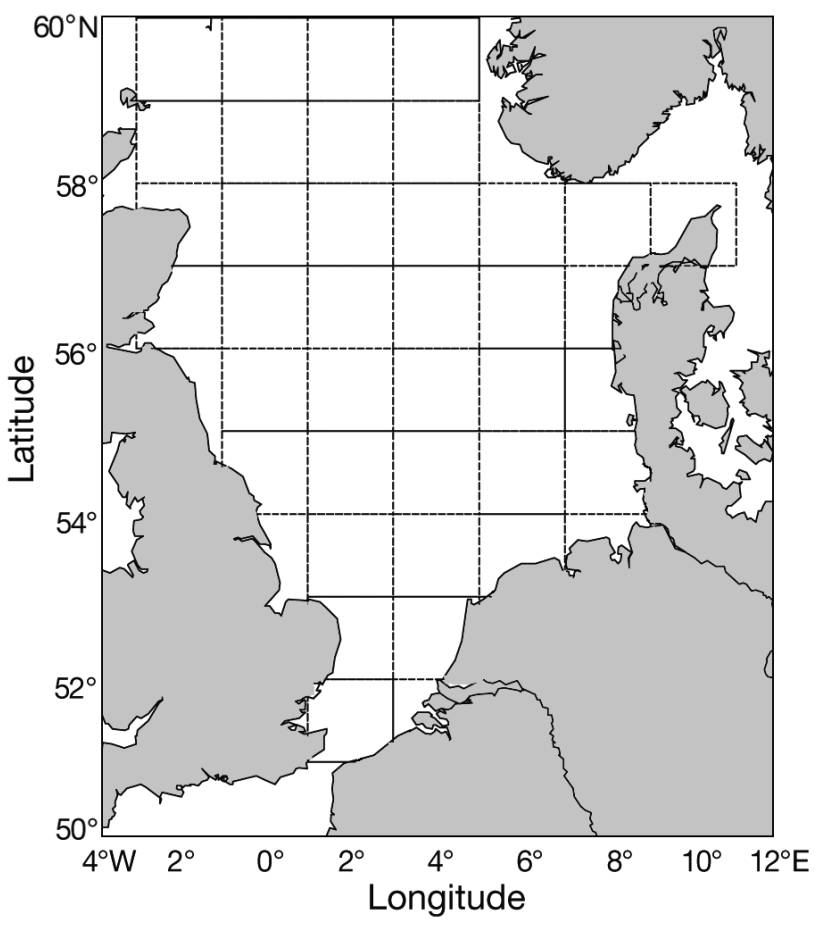

Fig. 2. Rectangular areas $(60 \times 60 \mathrm{n}$ miles each) in the North Sea used to calculate the average food composition and trawl catch

each area at a particular year and quarter. When ratios are examined, the ratio $n_{j}: n_{i}$ is given by the ratio $n_{i}: n_{j}$, and including both in an analysis is not appropriate. To avoid this, the analyses were performed separately for each denominator species size group (Prey $j$ ), referred to as reference species in the following. As the spatial distribution of prey differs between species, and the size of prey eaten depends on the size of the predator, it was necessary to use more than one reference species and size to ensure that the observations covered all areas of the North Sea and all predator size classes. Accordingly, the 6 most frequent length groups of the prey species were chosen as reference groups (j's). These consisted of Norway pout length groups 7.5 , 12.5 and $17.5 \mathrm{~cm}$ and whiting length groups $12.5,17.5$ and $22.5 \mathrm{~cm}$ (midpoints of $5 \mathrm{~cm}$ intervals), and thus covered both northern (Norway pout) and more southern (whiting) prey. The number of individuals recorded for length groups of other prey species was expressed relative to the number of prey items recorded in these groups. When a prey group was either not found in any of the stomachs sampled or not present in any of the trawl hauls from an area, the data point was omitted. To ensure that no estimate of slope and intercept was based on less than 10 observations, only combinations of prey, reference and predator species and sizes for which more than 10 data points was obtained were retained for further analyses. The 
resulting data set consisted of paired observations of the natural log to the average number of each prey relative to the number of a reference prey in the trawl $\left(\ln \left[T_{i} T_{j}^{-1}\right]\right)$ and in the stomach contents of a given predator species and size $\left(\ln \left[n_{i} n_{j}^{-1}\right]\right)$. Each pair constituted data from a given area, year and quarter. For each value of $\ln \left(T_{i} T_{j}^{-1}\right)$, an estimate of the variance of this was estimated as

$$
V\left[\ln \left(\frac{\hat{T}_{i}}{\hat{T}_{j}}\right)\right]=V\left[\ln \left(\hat{T}_{i}\right)\right]+V\left[\ln \left(\hat{T}_{j}\right)\right]
$$

Estimation of parameters. Generalised linear models (McCullaugh \& Nelder 1989) were used to estimate the parameters in Eq. (9). These models allow differences in slopes and intercept between (e.g.) predators to be tested for statistical significance. In full notation the basic generalised linear model can be written as:

$$
\begin{aligned}
& \ln \left(\frac{n_{i, l}(i), p, l(p)}{n_{\text {ref }, p, l(p)}}\right)= \\
& k_{\text {ref }, i, l(i), p, l(p)}+b_{\text {ref }, i, l(i), p, l(p)} \times \ln \left(\frac{T_{i}}{T_{\text {ref }}}\right)+\varepsilon
\end{aligned}
$$

where ref is reference species and length (equivalent to $j$ in the above equations), $l$ is length, $p$ is predator species, $k=\ln (d)$ and $\varepsilon$ is a normal distributed error term.

If the stomachs collected from a given haul are independent subsamples of the diet composition, the variance of the prey ratio should decline with the number of stomachs sampled in an area. Stomachs sampled from individual predators caught in a particular haul cannot, however, always be considered to be independent subsamples of the predator population, as within haul variation is often much less than between haul variation at a certain time and place (Warren et al. 1994, Bogstad et al. 1995, Darbyson et al. 2003). Nevertheless, as stomach contents are highly variable (Pennington et al. 1980), and as a single stomach is likely to contain less information about the diet composition than several stomachs, we decided to weight each data point with the number of stomachs sampled in the area at the given time. The parameters in the general linear model were estimated separately for each of the 6 prey reference groups. It was tested whether the parameter $b$ differed significantly between prey and predator species and sizes by analysing the significance of both direct and first and second order interaction effects of prey and predator species and sizes on the slope of the regression. Further, the significance of the effects of prey and predator species and size and first, second and third order interaction effects between these on the parameter $k$ were estimated. Due to the limited overlap between the predator length groups of cod and whiting, interaction effects between predator species and predator length group could not be examined.
Effect of variance of trawl catches. The regression analyses performed in this study are based on the assumption that the independent variable $x$ is known without error. However, if the independent variable has error attached to it, the ath observed value of $x_{1} x_{a t}$ is the sum of the true value, $\tau_{a l}$ and the error attached, $\delta_{a}$. Such error may lead to a bias in the estimate of $b$ (Draper \& Smith 1981). Assuming the covariance between $\tau$ and $\delta$ to be zero, the size of this bias can, however, be estimated as

where

$$
\frac{\hat{b}-b}{b}=\frac{\rho^{2}}{1+\rho^{2}}
$$

$$
\rho=\frac{\sigma_{\delta}}{\sigma_{\tau}}
$$

and $\sigma_{\tau}$ and $\sigma_{\delta}$ denote the standard deviation of $\tau$ and $\delta$, respectively (Draper \& Smith 1981). In the present study, both the independent variable $\left(\ln \left[T_{i} T_{r e f}{ }^{-1}\right]\right)$ and the variance of this have already been estimated. For each reference, we estimated $\sigma_{\tau}$ as the standard deviation of all observed values of

$$
\ln \left(\frac{\hat{T}_{i}}{\hat{T}_{\text {ref }}}\right)
$$

and $\sigma_{\delta}$ as the average standard deviation of $\delta$,

$$
\frac{1}{N} \sum_{a=1}^{N} V\left[x_{a}\right]^{0.5}
$$

where $N$ is the number of observations, $V\left[x_{a}\right]$ is

$$
V\left[\ln \left(\frac{\hat{T}_{i}}{\hat{T}_{\text {ref }}}\right)\right]
$$

and a denotes each combination of area, year, quarter and Prey Type $i$.

Effect of number of stomachs in sample. The estimates of $b$ could potentially be biased by averaging the food intake of a number of predator stomach samples. Chesson (1984) demonstrated that negative switching could arise as a mathematical artefact caused by pooling diet data from predators which differed in their individual prey preferences. Thus, even though the individuals do not exhibit switching, pooling them in the analysis could introduce negative switching at the population level. A separate analysis was therefore performed to investigate if the estimates of $k$ and $b$ depended on the number of stomachs in each sample. The basic model in Eq. (10) was modified slightly to allow a log-linear effect of number of stomachs in the sample on $k$ and $b$ :

$$
\begin{aligned}
& \ln \left(\frac{n_{i, l(i), p, l(p)}}{n_{\text {ref }, p, l(l)}}\right)=k_{\text {ref }, i, l(i), p, l(p)}+s_{\text {ref }} \times \ln \left(n s_{p, l(p)}\right)+ \\
& \left(b_{\text {ref }, i, l(l), p, l(p)}+s b_{\text {ref }} \times \ln \left(n s_{p, l l(p)}\right)\right) \times \ln \left(\frac{T_{i}}{T_{\text {ref }}}\right)+\varepsilon
\end{aligned}
$$


where $n s_{p, l(p)}$ is the number of stomachs sampled in the area at the given time and $s$ and $s b$ are additional parameters to be estimated in the model.

The factors tested for effects on $k$ and $b$ were the same as in the basic model. The $s$ and $s b$ parameters, describing the effect of number of stomachs in the sample on intercept and slope $(b)$ of the model respectively, were assumed to be constant within each reference group, and no interaction effects were tested; 1 analysis was performed for each reference as described above. To avoid spurious correlations, observations were not weighted by the number of stomachs in the sample.

Effect of predator density. Predators may interfere with each other's feeding, as they spend an increasing amount of their time chasing conspecifics or as an increased predator density causes prey to spend a greater proportion of their time in refuges and shelters (Gillis \& Kramer 1987, Abrams \& Matsuda 1993, Walters \& Juanes 1993). Alternatively, the efficiency of the individual predators may improve when they forage in a group as compared to foraging individually (Major 1978, Pitcher et al. 1982). The former effect produces 'undermatching' of the predator to the resources and would produce negative switching. The degree of undermatching and hence negative switching should increase with increasing predator density (Gillis \& Kramer 1987). Increased efficiency at high predator densities should, in the absence of predator interference, lead the predators to forage together on the most abundant prey (Stephens \& Krebs 1986). This could lead to a positive relationship between the degree of switching and predator density. In order to reveal if any of these hypotheses were likely to describe the interactions between predators at high densities, the relationship between local predator density and the slope, $b$, was examined. This was done by including the number of predators as a variable in the model. The model was similar to the model used to investigate the effect of the number of stomachs in the sample, except that the number of stomachs was replaced by the average catch of the predator species, $n p$, in the area where the stomachs had been collected:

$$
\begin{aligned}
& \ln \left(\frac{n_{i, l(i), p, l(p)}}{n_{r e f, p, l(p)}}\right)=k_{r e f, i, l(i), p, l(p)}+r_{r e f} \times \ln \left(n p_{p}\right)+ \\
& \left(b_{r e f, i, l(i), p, l(p)}+r b_{r e f} \times \ln \left(n p_{p}\right)\right) \times \ln \left(\frac{T_{i}}{T_{r e f}}\right)+\varepsilon
\end{aligned}
$$

Factors tested for effects on $k$ and $b$ were the same as in the basic model. The parameters $r$ and $r b$, describing the effect of predator density on intercept and slope $(b)$ of the model, respectively, were assumed to be constant within each reference group, and no interaction effects with these were tested. A separate analysis was performed for each reference group and the number of stomachs in each sample was used to weight the observations.

Statistical analyses. All tests were performed with a significance level of $\alpha=0.05$ using $\mathrm{SAS}^{\oplus}$ Version 8 for Windows ${ }^{\circledR}$ (SAS Institute 1989). Factors, which did not have a significant effect ( $F$-test) were removed from the models. Residuals were tested for significant difference from a normal distribution (Shapiro-Wilks statistic) and plotted against the predicted values and against the independent continuous variables.

\section{RESULTS}

\section{Basic model}

The common slope $b$ was highly significant for all reference fishes $(p<0.0001)$. In 3 cases, either prey, predator length or both affected the slope significantly, while no significant cross-effects were found for the remaining 3 reference fishes. After insignificant factors had been removed, the model explained between 28 and $54 \%$ of the variation of the data for the 6 reference size-

Table 1. Summary of fit of basic models using Norway pout Trisopterus esmarkii and whiting Merlangius merlangus as reference prey species. Dimension: number of parameters estimated in reduced generalised linear model; $\mathrm{p}>F$ : probability of mean describing data better than the model: Lower, Upper: lower and upper 95\% confidence limits of parameter estimate. All estimates were significantly different from both 0 and 1 ( $<<0.0001) ; \mathrm{p}<\mathrm{W}$ : probability of residuals being normally distributed; Bias: bias

\begin{tabular}{|c|c|c|c|c|c|c|c|c|c|c|}
\hline $\begin{array}{l}\text { Reference } \\
\text { species }\end{array}$ & Length $(\mathrm{cm})$ & $\mathrm{n}$ & $\mathrm{r}^{2}$ & Dimension & $\mathrm{p}>F$ & $b$ & Lower & Upper & $\mathrm{p}<\mathrm{W}$ & Bias \\
\hline Norway pout & 7.5 & 563 & 0.542 & 27 & $<0.0001$ & $0.350^{\mathrm{a}}$ & 0.310 & 0.390 & 0.0350 & -0.12 \\
\hline Norway pout & 12.5 & 794 & 0.581 & 21 & $<0.0001$ & 0.332 & 0.300 & 0.364 & 0.6379 & -0.14 \\
\hline Norway pout & 17.5 & 248 & 0.375 & 8 & $<0.0001$ & 0.280 & 0.205 & 0.355 & 0.2596 & -0.17 \\
\hline Whiting & 12.5 & 300 & 0.454 & 17 & $<0.0001$ & $0.214^{\mathrm{a}}$ & 0.166 & 0.262 & 0.3170 & -0.10 \\
\hline Whiting & 17.5 & 312 & 0.280 & 12 & $<0.0001$ & 0.218 & 0.173 & 0.263 & 0.4107 & -0.10 \\
\hline Whiting & 22.5 & 349 & 0.336 & 19 & $<0.0001$ & $0.145^{\mathrm{a}}$ & 0.081 & 0.209 & 0.7134 & -0.12 \\
\hline
\end{tabular}
introduced by disregarding error in trawl catches. n: no. of observations 
groups (Table 1). Selected examples of the relationship between log stomach content and trawl catch ratios are shown in Fig. 3. Approximately $20 \%$ of the total variation in the relative stomach content was explained by the relative survey catch alone for all reference fishes (Fig. 4). Because the significant effects were not the same for all reference fishes, it was difficult to compare the parameter estimates. However, the $95 \%$ confidence limit of the switching coefficient (ignoring interaction effects) had a maximum value of 0.390 and a minimum of 0.081 , corresponding to significant negative prey switching by both predators (Table 1).

The variance of the residuals was expected to decrease with increasing number of stomachs sampled in an area as the random variation in food composition should decrease with increasing sample size. This was far from being the case (Fig. 5). Rather, the variance of the residuals was largely constant irrespective of sample size. Inspection of residuals as a function of $\ln \left(T_{i} T_{\text {ref }}{ }^{-1}\right)$ revealed no trends which could indicate that the switching model used in the present study provided an inadequate description of the data (Fig. 5). The distribution of the residuals differed significantly from a normal distribution only for the reference Norway pout of $7.5 \mathrm{~cm}$.
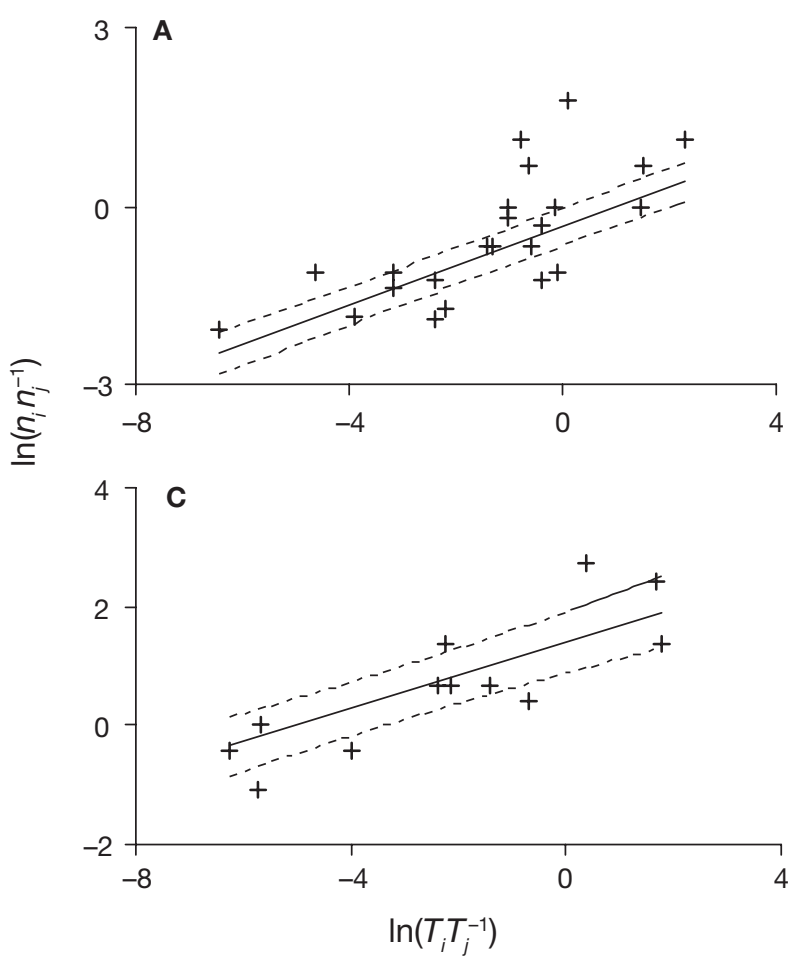

\section{Effect of variance of trawl catches}

The bias introduced by the error in trawl catches was minor (Table 1). In no case was the bias large enough to suggest that the confidence limits of the true value of $b$ would include 1 .

\section{Effect of number of stomachs in sample}

The number of stomachs in the sample had a positive effect on the slope, $b$, for all reference fishes, but the effect was only significant for the Norway pout specimens (Table 2). In those cases where the effect was significant, the slope increased by 0.091 on average each time the natural log to the number of stomachs in the sample increased by 1 . The generation of a slope equal to 1 would hence theoretically require more than 180000 stomachs in a single sample. At the observed mean and maximum sample size (20 and 99 stomachs, respectively), the slopes were 0.297 and 0.442 $(0.091 \ln (20)$ and $0.091 \ln (99)$, respectively, where 0.091 is the average $s b$ between the 3 Norway pout references).
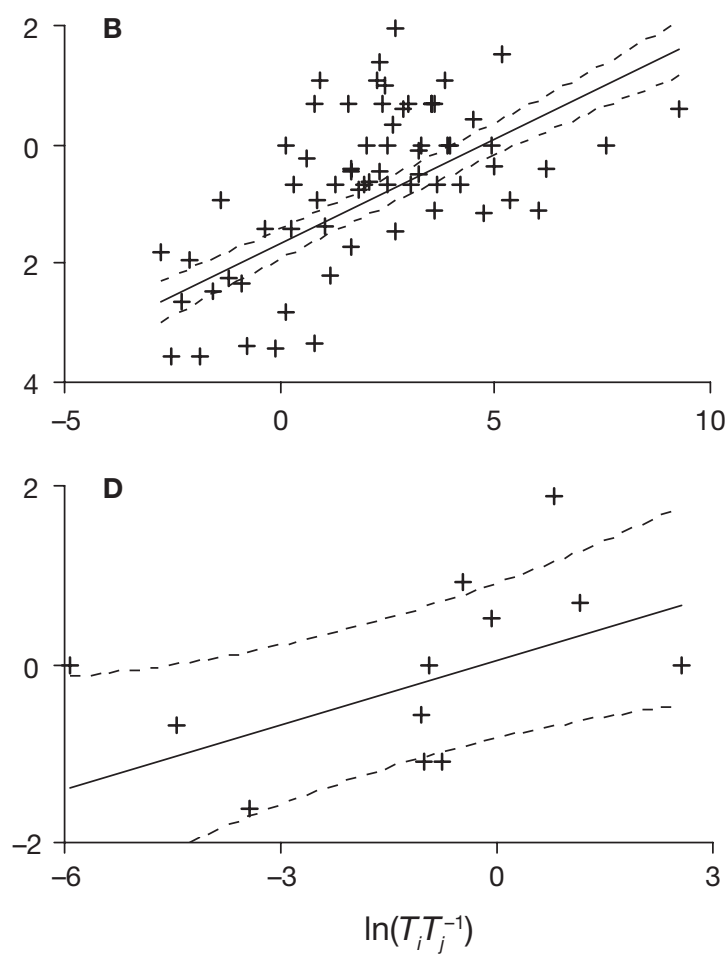

Fig. 3. Examples of $\log$ stomach contents, $\ln \left(n_{i} n_{j}^{-1}\right)$, as a function of cod Gadus morhua and whiting Merlangius merlangus $\ln \left(T_{i} T_{j}^{-1}\right)$. (+) observed; continuous curve: predicted by reduced model ${ }_{i}$ dotted curve $95 \%$ confidence limits of predicted line. Prey were haddock Melanogrammus aeglefinus, herring Clupea harengus, Norway pout Trisopterus esmarkii. (A) Haddock (12.5 cm): Norway pout $(12.5 \mathrm{~cm})$ eaten by cod $(35 \mathrm{~cm}) ;(B)$ Norway pout $(12.5: 7.5 \mathrm{~cm})$ eaten by whiting $(25 \mathrm{~cm}) ;(C)$ Herring $(22.5 \mathrm{~cm})$ : Norway pout $(17.5 \mathrm{~cm})$ eaten by cod $(85 \mathrm{~cm})$; (D) Haddock $(17.5 \mathrm{~cm})$ : whiting $(22.5 \mathrm{~cm})$ eaten by cod $(85 \mathrm{~cm})$ 


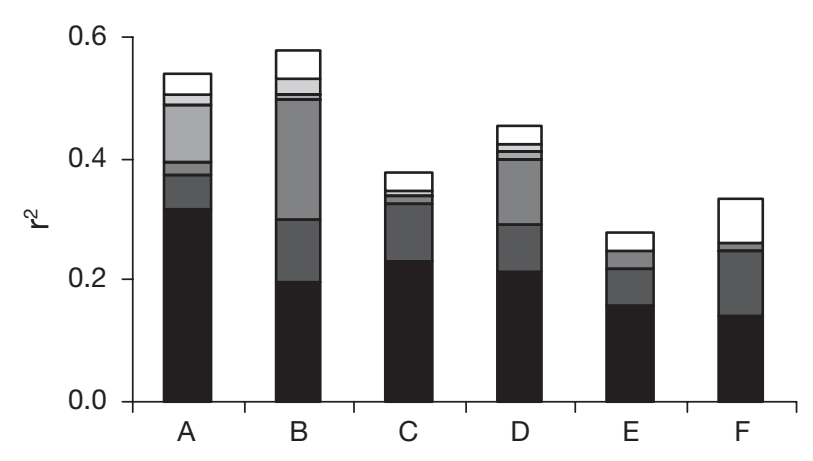

Fig. 4. Average proportion of total variation in stomach contents of cod and whiting, $\ln \left(n_{i} n_{j}^{-1}\right)$ explained by $(\boldsymbol{\square}) \ln \left(T_{i} T_{j}^{-1}\right)$, $(\square)$ prey species, $(\square)$ prey length, $(\square)$ predator species, $(\square)$ predator length and ( $\square$ ) crossed effects for different reference fishes. (A to C) Norway pout Trisopterus esmarkii of 7.5, 12.5 and $17.5 \mathrm{~cm}$, respectively; (D to F) whiting Merlangius merlangus of $12.5,17.5$ and $22.5 \mathrm{~cm}$, respectively
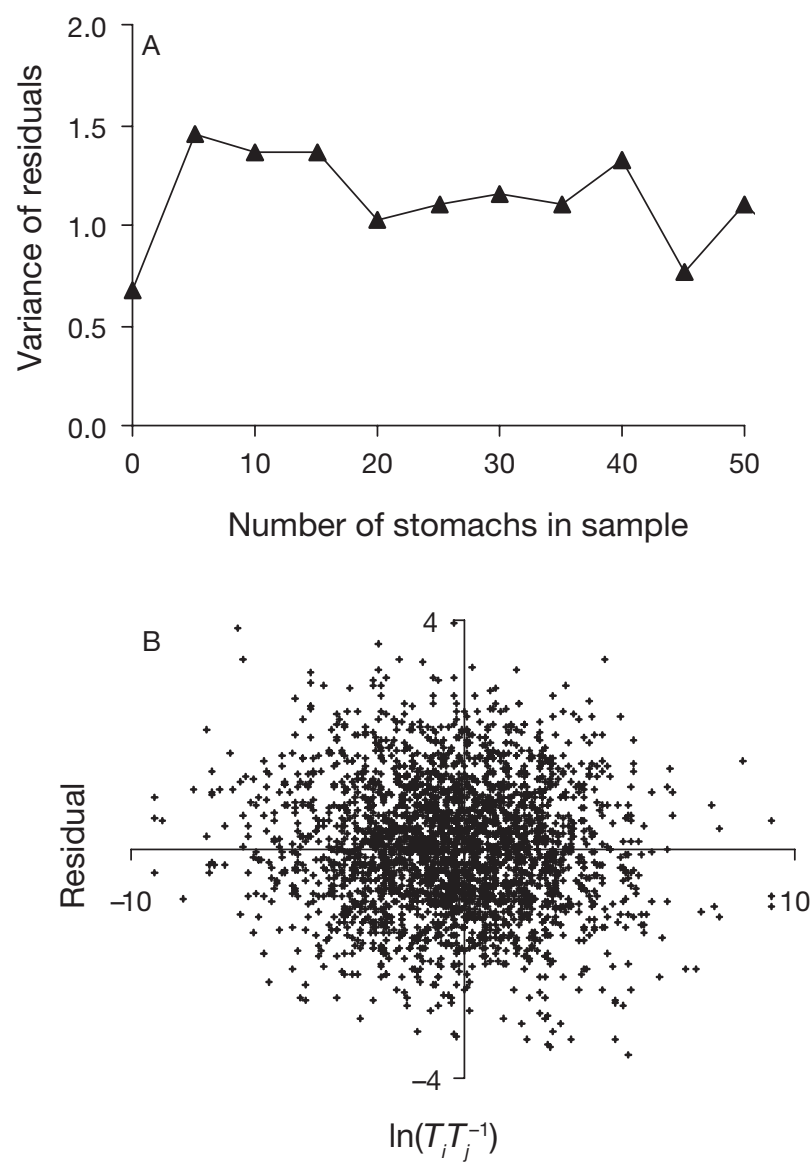

Fig. 5. (A) Variance in residuals from basic model as a function of number of stomachs in the sample (estimated within groups of $0-2,3-7,8-12$ etc.); (B) residuals from basic model as a function of $\ln \left(T_{i} T_{j}^{-1}\right)$
Table 2. Trisopterus esmarkii and Merlangius merlangus. Parameter estimates of $s b$ and $r b$. Values significant at $5 \%$ level are in boldface. ${ }^{*}$ Significant at $5 \%$ level $_{i}{ }^{* *}$ significant at $1 \%$ level $_{i}{ }^{* * *}$ significant at $0.1 \%$ level

\begin{tabular}{|lccc|}
\hline $\begin{array}{l}\text { Reference } \\
\text { species }\end{array}$ & Length $(\mathrm{cm})$ & $s b$ & $r b$ \\
\hline Norway pout & 7.5 & $\mathbf{0 . 1 0 9}^{* *}$ & 0.009 \\
Norway pout & 12.5 & $\mathbf{0 . 0 9 1}^{* * *}$ & 0.031 \\
Norway pout & 17.5 & $\mathbf{0 . 0 7 3}^{*}$ & 0.051 \\
Whiting & 12.5 & 0.034 & 0.021 \\
Whiting & 17.5 & 0.042 & 0.077 \\
Whiting & 22.5 & 0.037 & 0.075 \\
\hline
\end{tabular}

\section{Effect of predator density}

Although predator density had a positive effect on $b$ in all cases, none of the reference fishes were significantly affected by this factor (Table 2).

\section{DISCUSSION}

Negative switching was found in all the analyses in this study. This result is in agreement with a preliminary study by Larsen \& Gislason (1992), who compared the food composition of North Sea cod and whiting with model-based population estimates of their fish prey and found that a food selection model with negative switching provided the best fit to the data. In their analysis, the minimum of the squared deviation between estimated and observed food compositions of cod corresponded to a $b$ of around 0.5 , whereas the squared deviation for whiting continued to decline as the switching parameter was decreased to a $b$ of 0.4 , the lowest value tested. Similarly, with 1 exception, analyses of the feeding of gadoid species in the Celtic Sea did not reveal significant positive correlations between the proportion of prey in the diet and the abundance of this prey (Pinnegar et al. 2003), the result expected if the predators exhibit negative switching.

Although reports of negative switching are uncommon in the literature, Visser (1981) and Kean-Howie et al. (1988) found negative switching in 3-spined sticklebacks Gasterosteus aculeatus feeding on small invertebrates and fish larvae, and Reed (1969, cited in Murdoch \& Oaten 1975) observed a weak tendency to negative switching in bluegill sunfish Lepomis macrochirus feeding on insect larvae. Other authors have examined the presence or absence of positive switching in bluefish Pomatomus saltatrix and 3-spined sticklebacks, and although the authors do not conclude this directly, a closer examination of their results actually reveals negative switching (Gotceitas \& Brown 1993, 
Buckel \& Stoner 2000). From values in Fig. 3 of Buckel \& Stoner (2000) and in Fig. 4 of Gotceitas \& Brown (1993), estimates of $b$ of around 0.6 and 0.4 for bluegills and sticklebacks, respectively, can be derived.

There may be numerous explanations for the negative switching observed in the present study. Firstly, the results may reflect a genuine biological effect of increased relative prey density such as changes in the prey preferences of the predator or in predator-prey encounter rates. Decreased preference for the most abundant prey was suggested by Kean-Howie et al. (1988) to be a result of interference by the most abundant, but less preferred, prey in the predator's search at high prey densities. However, as juvenile gadoid prey do not differ extensively in appearance, the theory of confusion of the predator's search image is probably unlikely to provide the explanation of the present results. Another biological effect which may cause decreased preference for the most abundant prey is changes in prey behaviour as the prey attempts to reduce the encounter rate in situations where predation risk is high (Abrams \& Matsuda 1993, Walters \& Juanes 1993). However, as no evidence was found to suggest a negative correlation between $b$ and predator densities and hence mortality risk, this explanation is unlikely to apply in the present case. Similarly, pooling predator individuals with different preferences in the samples tended to increase $b$ and did not appear to cause negative switching, as suggested by Chesson (1984). The positive correlation between sample size and $b$ may be an effect of the limited stomach volume of the predator. A saturated predator will attain a maximum prey ratio determined by the maximum number of prey individuals its stomach can contain, and this will tend to lower the slope. As increasing the number of stomachs will increase the potential number of prey items in the sample, sample size would have a positive effect on the slope by increasing the maximum ratios observed. Lastly, if prey vulnerability decreases as prey density increases, this will lead to negative switching, as the encounter rate of the prey and individual predator will not then be proportional to the density of the prey. If prey, therefore, tend to be less vulnerable at high densities, perhaps due to the formation of larger schools or shoals, the predator will exhibit negative switching although no changes in prey preference occur.

An important assumption in the present study is that trawl catchability is independent of density. Although increasing catchability with abundance has been reported for larger $(>30 \mathrm{~cm}$ ) cod and haddock (Godø et al. 1999), these 2 species were rarely encountered in the stomachs at lengths $>30 \mathrm{~cm}$. The bias introduced by the error around trawl catch ratios was found to be a minor problem, not nearly large enough to cause the degree of negative switching seen here. The individual stomachs did not appear to be independent subsamples of the prey ratios, as the variance of the residuals did not decrease as expected with an increasing number of stomachs sampled (Fig. 5). Most probably this was caused by intra-haul correlation (Bogstad et al. 1995, Darbyson et al. 2003). However, weighting tended to decrease the estimate of $b$ only slightly compared to the unweighted estimate (compare the estimate obtained in the basic model (weighted) with that obtained in the model examining the effect of the number of stomachs in the sample (unweighted)).

The scale at which food intake and prey density should be compared has been discussed by several authors (Rose \& Leggett 1990). In our study, the scale was far greater than the perceptive abilities of the predators, and it is unlikely that all prey were available to all predators. However, the implications of the results for the population interactions between the predators and their prey are unaffected by the underlying mechanisms which produce negative switching. Furthermore, we arrived at essentially the same results if we combined the data on larger spatial scales (8 subareas of the North Sea, results not shown). Hence, although the assumptions made during this study may not all have been fulfilled, relaxing them within a reasonable range does not alter the conclusion that negative switching seemed to be the dominant response.

Positive switching generally stabilises otherwise unstable predator-prey equilibria, promotes coexistence of competitors, and increases the overall stability of linked predator-prey population models (May 1977, Abrams \& Matsuda 1996, Pelletier 2000), although recent studies of models in which the predators utilise adaptive diet selection (Abrams 1999) or optimal foraging strategies (van Baalen et al. 2001) have shown that this may not always be the case. Predators exhibiting negative switching will act in the opposite way. The diet composition of such predators will change comparatively little in response to changes in the relative abundance of their prey. If changes in the total food intake of the predator or in the overlap between the predator and the prey do not compensate for this, the predation mortality experienced by a particular prey group will increase when its abundance decreases. In fish populations, a small year class should thus suffer a higher predation mortality than a large year class. This seems to run contrary to the results obtained by field studies of marine fish populations. Myers \& Cadigan (1993) compared survey indices of year class strength for a large number of demersal fish stocks and found evidence of higher total mortality of large than of small year classes. Similar observations have been made for plaice Pleuronectes platessa (Lockwood 1980), coastal cod Gadus morhua 
(Bjørnstad et al. 1999) and 2 species of gobies, Coryphopterus glaucofraenum and Sagamia geneionema (Forrester 1995, Sano 1997) among others. Most authors suggest that predation would be the primary contributor to density dependent mortality for marine fishes (van der Veer et al. 1991, Forrester 1995, Sano 1997). This does not agree with the food selection model found here, unless the direct response of the predators is counteracted by compensatory changes in spatial overlap and total food intake, or density dependence regulates only younger stages which have not yet settled to the demersal layer. Hence, although the biological mechanisms which lead to negative switching remain to be determined, the present results render it highly unlikely that demersal prey selection alone is responsible for the persistence and apparent stability of the North Sea fish community throughout most of this century (Greenstreet \& Hall 1996). How negative prey switching, changes in total food intake, and changes in the spatial distribution of predators and prey jointly affect of the North Sea fish community remains to be determined.

Acknowledgements. We thank ICES for permission to use the data from the 'International Bottom Trawl Survey' and the coordinators of the 'ICES Stomach Sampling Project' for their efforts. J. Rice and 3 anonymous referees provided useful comments on an earlier draft. The research was supported by the SLIP research school under the Danish Network for Fisheries and Aquaculture Research (www.fishnet.dk) financed by the Danish Ministry for Food, Agriculture and Fisheries and the Danish Agricultural and Veterinary Research Council.

\section{LITERATURE CITED}

Abrams P (1999) The adaptive dynamics of consumer choice. Am Nat 153:83-97

Abrams P, Matsuda H (1993) Effects of adaptive predatory and anti-predatory behaviour in a two-prey-one-predator system. Evol Ecol 7:312-326

Abrams P, Matsuda H (1996) Positive indirect effects between prey species that share predators. Ecology 77:610-616

Armstrong MJ (1982) The predator-prey relationships of Irish Sea poor-cod (Trisopterus minutes L.), pouting (Trisopterus luscus L.), and cod (Gadus morhua L.). J Cons Int Explor Mer 40:132-152

Bence JR, Murdoch WW (1986) Prey size selection by the mosquitofish: relation to optimal foraging theory. Ecology 67:324-336

Bjørnstad ON, Fromentin J-M, Stenseth NC, Gjøsæter J (1999) A new test for density-dependent survival: the case of coastal cod populations. Ecology 80:1278-1288

Bogstad B, Pennington M, Vølstad JH (1995) Cost-efficient survey designs for estimating food consumption by fish. Fish Res 23:37-46

Buckel JA, Stoner AW (2000) Functional response and switching behavior of young-of-the-year piscivorous bluefish. J Exp Mar Biol Ecol 245:25-41
Chesson J (1989) The effect of alternative prey on the functional response of Notonecta hoffmani. Ecology 70:1227-1235

Chesson PL (1978) Predator-prey theory and variability. Annu Rev Ecol Syst 9:323-347

Chesson PL (1984) Variable predators and switching behavior. Theor Popul Biol 26:1-26

Darbyson E, Swain DP, Chabot D, Castonguay M (2003) Diel variation in feeding rate and prey composition of herring and mackerel in the southern Gulf of St Lawrence. J Fish Biol 63:1235-1257

Draper NR, Smith H (1981) Applied regression analysis. 2nd edn. John Wiley \& Sons, New York

Elton RA, Greenwood JJD (1970) Exploring apostatic selection. Heredity 25:629-633

Essington TE, Hodgson JR, Kitchell JF (2000) Role of satiation in the functional response of a piscivore, largemouth bass (Micropterus salmoides). Can J Fish Aquat Sci 57:548-556

Forrester GE (1995) Strong density-dependent survival and recruitment regulate the abundance of a coral reef fish. Oecologia 103:275-282

Gillis DM, Kramer DL (1987) Ideal interference distributions: population density and patch use by zebrafish. Anim Behav 35:1875-1882

Godø OR, Walsh SJ, Engås A (1999) Investigating densitydependent catchability in bottom-trawl surveys. ICES J Mar Sci 56:292-298

Gotceitas V, Brown JA (1993) Risk of predation to fish larvae in the presence of alternative prey: effects of prey size and number. Mar Ecol Prog Ser 98:215-222

Greenstreet SPR, Hall SJ (1996) Fishing and the ground-fish assemblage structure in the north-western North Sea: an analysis of long-term and spatial trends. J Anim Ecol 65: 577-598

Hart PJB, Ison S (1991) The influence of prey size and abundance, and individual phenotype on prey choice by the three-spined stickleback, Gasterosteus aculeatus L. J Fish Biol 38:359-372

Hawkins AD, Soofiani NM, Smith GW (1985) Growth and feeding of juvenile cod, Gadus morhua (L). J Cons Int Explor Mer 42:11-32

Hilborn R, Mangel M (1997) The ecological detective. Confronting models with data. Princeton University Press, Princeton, NJ

Hislop JRG, Robb AP, Bell MA, Armstrong DW (1991) The diet and food consumption of whiting (Merlangius merlangus) in the North Sea. ICES J Mar Sci 48:139-156

Holt RD (1983) Optimal foraging and the form of the predator isocline. Am Nat 122:521-541

ICES (1988) Report of the meeting of the coordinators in the stomach sampling project 1985 to 1987. Int Counc Explor Sea Comm Meet 1988/G:27

ICES (1989) Database report of the stomach sampling project 1981. Int Counc Explor Sea Coop Res Rep 164

ICES (1991) Manual for the ICES North Sea stomach sampling project in 1991. Int Counc Explor Sea Comm Meet 1991/G:3

ICES (1992) Progress report on the ICES 1991 North Sea stomach sampling project. Int Counc Explor Sea Comm Meet 1992/G:12

ICES (1996a) Report of the International Bottom Trawl Survey Working Group. Int Counc Explor Sea Comm Meet 1996/H:1

ICES (1996b) Manual for the international bottom trawl survey. Revision V. Addendum to Int Counc Explor Sea Comm Meet 1996/H:1(Addendum)

ICES (1997) Database report of the stomach sampling project, 1991. Int Counc Explor Sea Coop Res Rep 219 
Kean-Howie JC, Pearre S Jr, Dickie LM (1988) Experimental predation by sticklebacks on larval mackerel and protection of fish larvae by zooplankton alternative prey. J Exp Mar Biol Ecol 124:239-259

Kikkert AH (1993) Analysis of the cod samples collected in the North Sea during the 1991 international stomach sampling project. Int Counc Explor Sea Comm Meet 1993/ G:13

Larsen JR, Gislason H (1992) MSVPA and prey/predator switching. Int Counc Explor Sea Comm Meet 1992/G:42

Lipcius RN, Hines AH (1986) Variable functional responses of a marine predator in dissimilar homogeneous microhabitats. Ecology 67:1361-1371

Lockwood SJ (1980) Density-dependent mortality in O-group plaice (Pleuronectes platessa L.) populations. J Cons Int Explor Mer 39:148-153

Major PF (1978) Predator-prey interactions in two schooling fishes, Caranx ignobilis and Stolephorus purpureus. Anim Behav 26:760-777

Manly BFJ, Miller P, Cook LM (1972) Analysis of a selective predation experiment. Am Nat 106:719-736

May RM (1977) Predators that switch. Nature 269:103-104

McCullaugh P, Nelder JA (1989) Generalized linear models. Monogr Stat Appl Probab 37

Murdoch WW (1969) Switching in general predators: experiments on predator specificity and stability of prey populations. Ecol Monogr 39:335-354

Murdoch WW, Oaten A (1975) Predation and population stability. Adv Ecol Res 9:1-130

Murdoch WW, Avery S, Smyth MEB (1975) Switching in predatory fish. Ecology 56:1094-1105

Myers RA, Cadigan NG (1993) Density-dependent juvenile mortality in marine demersal fish. Can J Fish Aquat Sci 50: 1576-1590

Pelletier JD (2000) Are large complex ecosystems more unstable? A theoretical assessment with predator switching. Math Biosci 163:91-96

Pennington M (1983) Efficient estimators of abundance for fish and plankton surveys. Biometrics 39:281-286

Pennington M (1986) Some statistical techniques for estimating abundance indices from trawl surveys. Fish Bull (Wash DC) 84:519-525

Pennington M, Bowman R, Langton R (1980) Variability of the weight of stomach contents of fish and its implications for food studies. Int Counc Explor Sea Comm Meet 1980/L:63

Pinnegar J K, Trenkel VM, Tidd AN, Dawson WA, Du Buit MH (2003) Does diet in Celtic Sea fishes reflect prey availability? J Fish Biol A 63:197-212

Pitcher TJ, Magurran AE, Winfield IJ (1982) Fish in larger shoals find food faster. Behav Ecol Sociobiol 10:149-151

Editorial responsibility: Howard Browman (Associate Editorin-Chief), Storebø, Norway
Quinn TJ, Deriso RB (1999) Quantitative fish dynamics. Oxford University Press, New York

Robb AP (1992) Changes in the gall bladder of whiting (Merlangius merlangus) in relation to recent feeding history. Int Counc Explor Sea J Mar Sci 49:431-436

Rose GA, Leggett WC (1990) The importance of scale to predator-prey spatial correlations: an example of Atlantic fishes. Ecology 71:33-43

Sano M (1997) Temporal variation in density dependence: recruitment and postrecruitment demography of a temperate zone sand goby. J Exp Mar Biol Ecol 214:67-84

SAS Institute (1989) SAS/STAT ${ }^{\circledR}$ User's guide, Version 6, 4th edn, Vol 1. SAS Institute, Cary, NC

Seyhan K, Grove DJ (1998) Food consumption of whiting, Merlangius merlangus, in the Eastern Irish Sea. Fish Res 38:233-245

Stefánsson G (1996) Analysis of groundfish survey abundance data: combining the GLM and delta approaches. Int Counc Explor Sea J Mar Sci 53:577-588

Stefánsson G, Pálsson OK (1997) Statistical evaluation and modelling of the stomach contents of Icelandic cod (Gadus morhua). Can J Fish Aquat Sci 54:169-181

Stephens DW, Krebs JR (1986) Foraging theory. Princeton University Press, Princeton, NJ

Townsend CR, Risebrow AJ (1982) The influence of light level on the functional response of a zooplanktonivorous fish. Oecologia 53:293-295

van Baalen M, Kfiivan V, van Rijn PCJ, Sabelis MW (2001) Alternative food, switching predators, and the persistence of predator-prey systems. Am Nat 157:512-524

van der Veer HW, Bergman MJN, Dapper R, Witte JIJ (1991) Population dynamics of an intertidal 0-group flounder Platichthys flesus population in the western Dutch Wadden Sea. Mar Ecol Prog Ser 73:141-148

Visser M (1981) Prediction of switching and counterswitching based on optimal foraging. Z Tierpsychol 55: 129-138

Visser M (1982) Prey selection by the three-spined stickleback (Gasterosteus aculeatus L.). Oecologia 55:395-402

Walters CJ, Juanes F (1993) Recruitment limitation as a consequence of natural selection for use of restricted feeding habitats and predation risk taken by juvenile fishes. Can J Fish Aquat Sci 50:2058-2070

Warren WG, Lilly GR, Shelton PS (1994) Estimating the population mean stomach content weight of cod from a stratified- random trawl survey and length stratified stomach sampling. Int Counc Explor Sea Comm Meet 1994/D:13

Werner EE, Hall JD (1974) Optimal foraging and the size selection of prey by the bluegill sunfish (Lepomis macrochirus). Ecology 55:1042-1052

Submitted: October 19, 2005; Accepted: February 23, 2006 Proofs received from author(s): October 2, 2006 